\title{
PARAMETER IDENTIFICATION OF A FIRE TRUCK SUSPENSION FOR VIBRATION ANALYSIS
}

\author{
${ }^{1}$ Flóra HAJDU,${ }^{*}$ Péter SZALAI, ${ }^{3}$ Péter MIKA, ${ }^{4}$ Rajmund KUTI \\ 1,2,3,4 Department of Mechatronics and Machine Design \\ Faculty of Mechanical Engineering, Informatics and Electrical Engineering \\ Széchenyi István University, Egyetem tér 1, H-9026 Győr, Hungary \\ e-mail: ${ }^{1}$ hajdfl@sze.hu, ${ }^{2}$ szalai@sze.hu, ${ }^{3}$ mika.peter@sze.hu, ${ }^{4}$ kuti.rajmund@sze.hu
}

Received 19 December 2018; accepted 11 March 2019

\begin{abstract}
In case of field measurement it is essential to determine the measurement conditions. With accurate parameter identification credible measurement and simulation results can be achieved. In this paper the parameter identification of a CSD-755-10 heavy-duty fire truck suspension for vibration analysis is presented, which is an important base-point for further research.
\end{abstract}

Keywords: Parameter identification, Fire truck, Harmful vibration, Least squares method

\section{Introduction}

In special purpose vehicles for example fire trucks high value equipment is built in. These devices can be damaged by various adverse effects, like harmful vibrations during operation of a fire truck, which must be continuously examined [1]. These vibrations can cause serious structural damage; therefore their examination is an important, current issue [2]-[3]. Analyzing the available literature on the topic it can be stated that similar measurements and tests were mostly carried out in laboratory conditions or in test track [4]-[7], field experiments were performed in a smaller number [8]-[9]. Most experiments were carried out with several different purpose trucks [4]-[9], but not with special fire trucks. Literature connected to firefighting is about firefighter training [10]-[11] or the development of rescue robots [12]. Field experiments can be carried out in a very wide spectrum. The output of the experiments, data analysis and

\footnotetext{
${ }^{*}$ Corresponding Author
} 
simulation results can be greatly influenced by predetermined test parameters. In this paper the parameter identification required for the vibration analysis of the CSD-755-10 fire truck is presented, the field measurement with real road profiles will be described in a further study.

\section{Parameter identification of vehicles}

Parameter identification is not a simple task since the appropriate method should be determined by knowing the task to be performed and ensuring the necessary conditions. Each test, measurement can be extremely complex and varied, therefore parameter identification has several well-known methods. In practical applications statistical parameter identification methods are widely used. In [13]-[14] a maximum likelihood estimation method is presented to identify the parameters of a bus based on AutoRegressive-Moving-Average (ARMA) and Auto-Regressive-Moving-Average model with eXogenous inputs (ARMAX) models. In [15] a mathematical model to identify the stiffness and damping of a heavy-duty truck suspension system is presented based on curve fitting method. Using curve fitting method the minimum of quadratic error function between the simulated seat vertical acceleration power spectral density and the measured power spectral density was taken. Publication [16] concerns exploitational identification of structural parameters of the Toyota Camry suspension system based on measured acceleration data. The developed algorithm combines the restoring force, boundary perturbation and direct parameter estimation techniques. In [17] a modified recursive least squares algorithm was adjusted with the forgetting factor and Kalman filter was used to identify the parameters of a motorcycle suspension system. Paper [18] presents a novel online method for identifying the mass of an off-road vehicle using acceleration measurements of sprung and unsprung mass using recursive least squares estimation. The developed method can be used for vehicle active safety control, traction control, and powertrain control. In [19] a novel parameter identification method for vehicle tracking using an extended Kalman filter and measurements of road surface vibrations is presented. In [20] a fast continuous time system identification is described using the half-vehicle model and a prediction error based method direct continuous time system identification to evaluate the vehicle's unknown parameters. The developed method was tested with simulation software CarMaker. In [21] a novel algebraic estimator is presented to find the unsprung mass of the suspension system. The purpose of this research was to improve passenger comfort with a sliding mode controller in simulation environment. In [22] the parameters of a heavy-duty truck engine mount are identified based on measurement data through optimization with Least Mean Square (LMS) algorithm. The main objective of the research was to develop an adaptronic engine mounting system in order to enhance driver comfort and handling of a heavy truck. In [23] the air temperature of the truck cabin was modeled with white-box and black-box techniques. For black-box modeling Matlab system identification toolbox was used, which estimates the parameters of the system with a least squares algorithm. With the same method the resistance of an electric vehicle battery was also identified using Simulink Parameter Estimation Toolbox [24]-[25]. Not only the parameters of a suspension system can be obtained with identification methods, but the characteristics 
of certain elements too in order to develop vehicle simulations. In [26] the damping characteristic of shock absorber of a heavy-duty truck suspension system was determined with the least squares method. Seven parameters of a Besinger model describing the shock absorbers nonlinear characteristics were identified based on measurements. Similar methods for parameter and model identification can be used in other engineering fields too like magnetic hysteresis modeling [27], [28] and for linear approximation of nonlinear systems [29].

In case of parameter identification the input and output of a system is known, but the behavior of the system is unknown. The aim is to establish a model that can fit to the measured data. If the system is entirely unknown it is called the 'black-box' parameter identification as it can be seen in Fig. 1 .

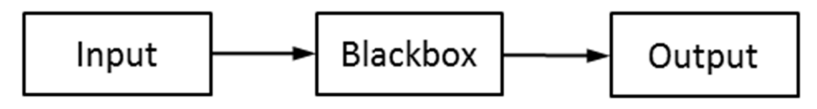

Fig. 1. Parameter identification

The task of the research is to examine the vibrations caused by the road during operation of the CSD 755-10 heavy-duty fire truck with measurements and simulation. To establish an accurate simulation model the parameters of the system need to be determined. For parameter identification the least squares parameter estimation method was chosen. The advantage of the method is that it can be easily implemented and the time domain measurements can be directly used. According to literature study it is one of the most common methods for parameter identification in vehicle development.

\subsection{Least squares parameter estimation}

In case of parameter identification the measurement data and the input signal are given. The behavior of the system can be described by mathematical equation with system variables. An optimization task is to be solved, which objective function is to minimize the sum of least squares [30],

$$
\text { objective function }=\operatorname{minimize} \sum_{i=1}^{m}(y(i)-x(i))^{2} \text {. }
$$

To solve the optimization task Matlab OPTI Toolbox was used. As solver NL2SOL adaptive nonlinear least squares algorithm was chosen, which is one of the best algorithm available [31].

\section{Measurement}

In Hungary, especially in case of low class roads, the participants of the traffic encounter a lot of surface defects and potholes. As first step the depth of several potholes around Györ was measured, the maximum depth was $10 \mathrm{~cm}$. At the same time 
the height of the curbs was also measured, which was also $10 \mathrm{~cm}$. Considering the above, it was decided to set up a $10 \mathrm{~cm}$ high artificial obstacle on which the vehicle would drive through.

The construction of CSD-755-10 fire truck suspension system can be seen in Fig. 2. The vehicle has a ladder frame chassis with beam axles. Suspension is provided by leaf springs for both axles and auxiliary leaf springs are installed in the rear axle because of constant load. Hydraulic shock absorbers are installed on both sides provide right road holding. The drive system is powered by a CUMMINS 6CT 8.3 diesel engine that drives the FP-2418 pump through a separate gear drive. The special firefighter equipment, which consists of a water tank, a foam tank and storing compartments is assembled to the chassis of the vehicle with a separate auxiliary chassis. The cabin is placed on rubber mount.
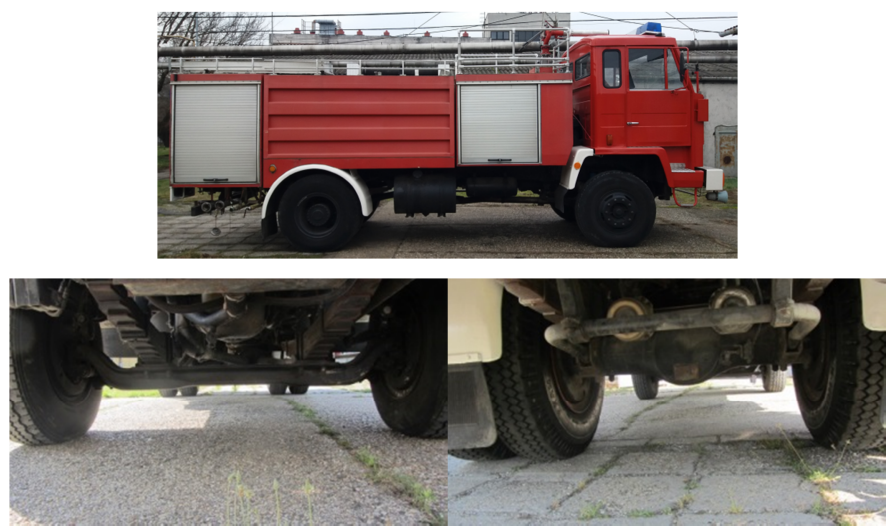

Fig. 2. CSD-755-10 fire truck

Before setting up the measurement accelerometer sensors were installed to the front and rear suspension at both sides as well as in the cabin and at the superstructure as it can be seen in Fig 3.

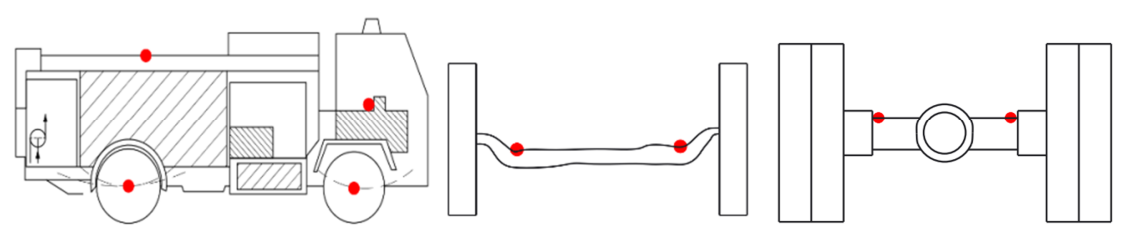

Fig. 3. Placement of vibration sensors on the vehicle

The used measuring instrument is:

- Brüel \&Kjaer 3560-C Frontend, Accelerometer sensors;

- Pulse Labshop 18, software. 
The measurement was carried out on a flat, straight, solid pavement. After installing the accelerometer sensors $10 \times 10 \mathrm{~cm}$ obstacles were placed on the selected road section on which the vehicle had to drive through at constant velocity during the test, which was specified as $5 \mathrm{~km} / \mathrm{h}$. $5 \mathrm{~km} / \mathrm{h}$ speed was chosen because it is the smallest speed that can be kept by the vehicle, and the tire and the chassis are not damaged during the jump. This was considered the starting point for the measurements. Two measurements were recorded. Both measurements were considered appropriate. From the acceleration data velocity and displacement data was calculated using integration. The measurement results can be seen in Fig. 4.
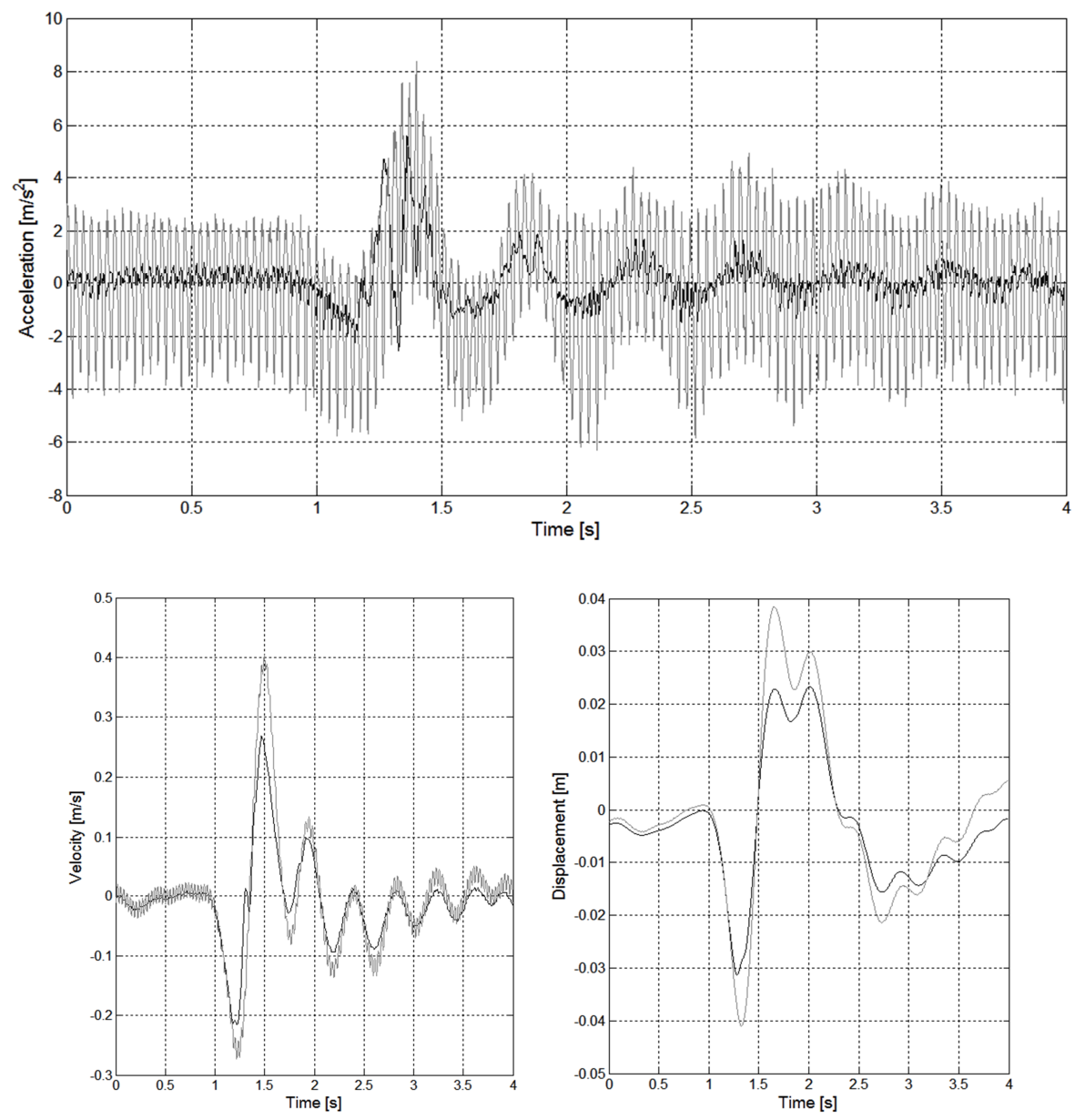

Fig. 4. Measurement results (up: acceleration, bottom left: velocity, bottom right: position, grey: superstructure, black: front axle) 
The measured signals were noisy; therefore prior to parameter identification the noise not related to the measurement should be filtered out. Noise filtering was carried out with Maple. First the frequency of the noise was determined by a fast Fourier transformation then a low pass filter was used to remove excess noise. Using the results remaining after the noise filtration computer simulation was carried out.

\section{Parameter estimation of a fire-truck}

\subsection{Modell}

In the literature quarter vehicle model was mostly used for parameter identification. Therefore in the first approach, the parameters of the front axle were determined using a linear and nonlinear quarter vehicle model presented in Fig. 5. The parameter identification of the fire truck using a half or full vehicle model will be the task of further research.

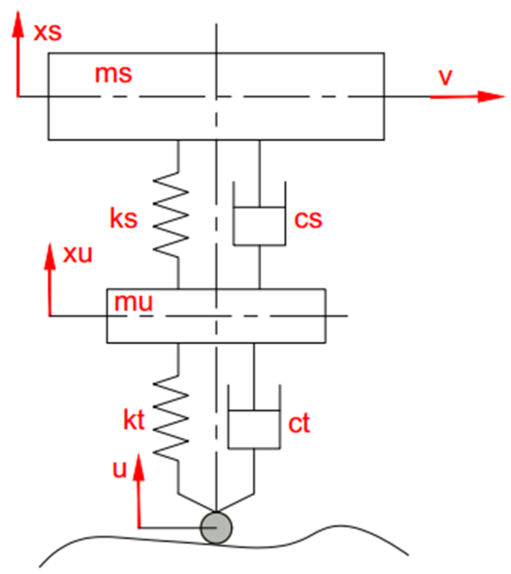

Fig. 5. Quarter car model

Behavior of the system can be described with the following equations:

$$
\begin{aligned}
& m_{S} \ddot{x}_{S}=c_{S}\left(\dot{x}_{u}-\dot{x}_{S}\right)+k_{S}\left(x_{u}-x_{S}\right), \\
& m_{u} \ddot{x_{u}}=-c_{S}\left(\dot{x}_{u}-\dot{x}_{S}\right)-k_{S}\left(x_{u}-x_{S}\right)+k_{t}\left(u-x_{u}\right)+c_{t}\left(\dot{u}-\dot{x}_{S}\right) .
\end{aligned}
$$

Equations describing the nonlinear characteristics of the spring and the damper are:

Pollack Periodica 14, 2019, 3 


$$
\begin{aligned}
& F_{k}=k_{i} \cdot \operatorname{sgn}(\Delta u)|\Delta u|^{n_{i}}, \\
& F_{c}=c \cdot \operatorname{sgn}\left(\Delta\left(\frac{d u}{d t}\right)\right)\left|\Delta\left(\frac{d u}{d t}\right)\right|^{n_{c s}} .
\end{aligned}
$$

The obstacle was modeled as a step function.

During parameter identification, several models were used. First a linear model without tire damping was applied, since according to the literature the damping of the tire is very small compared to the other parameters and is therefore neglected in some cases [32]-[34]. Next, the effect of tire damping was observed; taking this into account a better approximation could be achieved. Comparing the measured and simulation results a remaining sinusoidal signal was found. It was assumed that the sinusoidal signal could be generated from the road or from the vehicle, so the model was extended with a sinusoidal disturbance signal. The test models used during the identification were as follows:

1. Linear model without tire damping;

2. Linear model;

3. Nonlinear model;

4. Linear model with sinusoidal road disturbance;

5. Linear model with sinusoidal vehicle disturbance;

6. Nonlinear model with sinusoidal vehicle disturbance.

\subsection{Parameter identification with initial parameter values taken from literature}

For the first approximation, the initial parameter values were taken from [35] as it is shown in Table I.

Table I

Initial parameter values (from literature)

\begin{tabular}{|c|c|c||c|c|c|}
\hline Parameter & Value & Unit & Parameter & Value & Unit \\
\hline$m_{s}$ & 2500 & $\mathrm{~kg}$ & $c_{t}$ & 500 & $\mathrm{Ns} / \mathrm{m}$ \\
$m_{u}$ & 310 & $\mathrm{~kg}$ & $n_{k s}$ & 1.3 & \\
$k_{s}$ & 300000 & $\mathrm{~N} / \mathrm{m}$ & $n_{k t}$ & 1.1 & \\
$k_{t}$ & 1000000 & $\mathrm{~N} / \mathrm{m}$ & $n_{c s}$ & 2.2 & \\
$c_{s}$ & 20000 & $\mathrm{Ns} / \mathrm{m}$ & & & \\
\hline
\end{tabular}

The results of parameter identification are shown in Table II. The numbers show the test models described before and $\Sigma$ LS is the sum of least squares.

From Table II it can be concluded that the best approximation could be achieved by using a nonlinear model with sinusoidal noise from the vehicle (model 6). However, it can be stated that the spring stiffness was very low compared to the initial values and the other models. The damping of the tire was greater than the value obtained from the literature in each case. 
Table II

Results of parameter identification

\begin{tabular}{|c|c|c|c|c|c|c|}
\hline Parameter & 1 & 2 & 3 & 4 & 5 & 6 \\
\hline$k_{s}$ & 10000 & 10000 & 739230 & 10000 & 109190 & 44550 \\
$k_{t}$ & 44767 & 56741 & 10000 & 51287 & 57040 & 60183 \\
$c_{s}$ & 19882 & 62045 & 8800 & 90587 & 59960 & 8948 \\
$c_{t}$ & & 5000 & 5000 & 5000 & 5000 & 5000 \\
$n_{k s}$ & & & 1.7236 & & & 0.7978 \\
$n_{k t}$ & & & 0.6529 & & & 1.0199 \\
$n_{c s}$ & & & 0.3414 & & 0.4166 & 0.4166 \\
$\Sigma \mathrm{LS}$ & 45.4653 & 35.9316 & 43.9029 & 33.7879 & 32.2651 & 31.1266 \\
\hline
\end{tabular}

\subsection{Determining spring stiffness with other methods}

The stiffness of the leaf spring was determined with other methods too. Based on an analytical solution described in [36] the spring stiffness was calculated as $k=522845.5 \mathrm{~N} / \mathrm{m}$. This method has an advantage that only the geometry of the spring is necessary for calculation.

The spring stiffness was obtained by finite element simulation too [37]. The finite element model can be seen in Fig. 6. A remote displacement was constrained at the eyes and a force was given at the top leaf [38]. This is a simplified model as inter-leaf friction was not taken into account; contacts were modeled as no separation.

B Force: $10000 \mathrm{~N}$

C Remote Displacement

Demote Displacement2

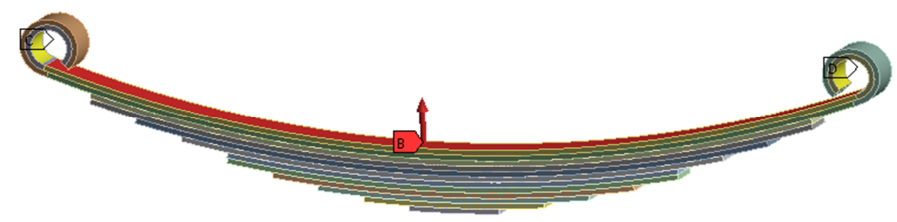

A: Static Structural (ANSYS)

Directional Deformat

Type: Directional Deformation ( $Y$ Avis)

Global Coordinote Sytem

Time: 1.12 .150 .12

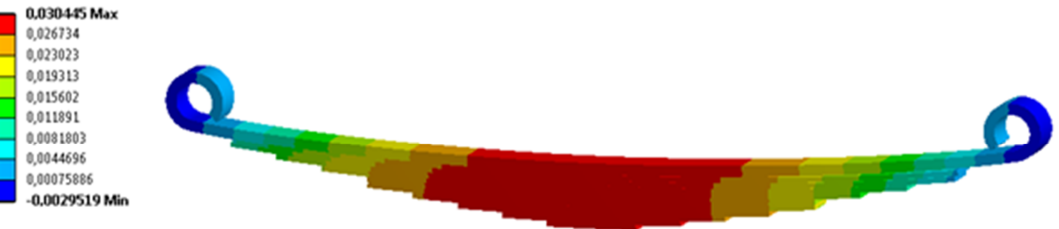

Fig. 6. Finite element model of the leaf spring

Pollack Periodica 14, 2019, 3 
The spring stiffness was calculated from the displacement:

$$
k=\frac{F}{\Delta x}=\frac{10000}{0.030455}=328407 \frac{\mathrm{N}}{\mathrm{m}} .
$$

Parameter identification was carried out with pre-determined spring stiffness values. In this case less unknown parameters had to be obtained. Results can be seen in Table III.

\section{Table III}

Parameter identification with pre-determined spring stiffness values

\begin{tabular}{|c|c|c|c|c|c|c|c|c|}
\hline & \multicolumn{4}{|c|}{$\mathrm{k}=522845.5 \mathrm{~N} / \mathrm{m}$} & \multicolumn{4}{c|}{$\mathrm{k}=328407 \mathrm{~N} / \mathrm{m}$} \\
\hline Parameter & 2 & 3 & 5 & 6 & 2 & 3 & 5 & 6 \\
\hline$k_{t}$ & 52780 & 10000 & 50300 & 27891 & 54070 & 10000 & 52510 & 32233 \\
\hline$c_{s}$ & 100000 & 12985 & 100000 & 12158 & 100000 & 10889 & 100000 & 9668 \\
\hline$c_{t}$ & 5000 & 5000 & 5000 & 5000 & 5000 & 5000 & 5000 & 5000 \\
\hline$n_{k s}$ & & 1.5868 & & 1.3827 & & 1.4063 & & 1.2600 \\
\hline$n_{k t}$ & & 0.8073 & & 0.7705 & & 0.7915 & & 0.8145 \\
\hline$n_{c s}$ & & 0.2479 & & 0.5009 & & 0.3334 & & 0.4245 \\
\hline$\Sigma \mathrm{LS}$ & 38.4924 & 55.4658 & 38.2348 & $\mathbf{3 1 . 6 3 6 1}$ & 38.4924 & 53.3742 & 33.7050 & $\mathbf{3 1 . 5 2 3 3}$ \\
\hline
\end{tabular}

Comparing the results it can be stated that the best fit was achieved with the nonlinear model, which takes the vehicle noise into account (model 6). At the same time it should be noted that, unlike expectations with less parameters better fit could not be achieved.

\subsection{Summary of results}

To summarize the results it can be concluded that the best fit could be achieved with the nonlinear model with sinusoidal vehicle noise. Compared to the parameter values taken from the literature the damping effect is greater. The stiffness of the tire was less than the value taken from the literature in all cases. From the nonlinear models it can be assumed that the leaf spring has progressive and the tire stiffness and the hydraulic shock absorber has degressive characteristics.

Comparing the methods it can be stated that in case of the analytical solution and the finite element analysis the geometric data is sufficient, it is not necessary to carry out expensive and time-consuming measurements, which is a great advantage. However, it should be noted that these are approximate models in which some external effects are neglected. Analyzing the data of the measurements, it can be seen that an unexpected sinusoidal effect emerged. This is an important observation as on the theoretical plane its consequences could not be detected. 


\section{Conclusion and further research tasks}

It can be concluded that accurate models and field measurements are indispensable for parameter identification and creating simulations for practical usage. With the experience gained during the present research, even more accurate measurements will be carried out in the future for more effective parameter identification.

In addition to the presented results, the recent research work has helped to identify future research tasks, which are parameter identification in the frequency domain, validation of the model based on measured data and using half-vehicle or full vehicle models for simulations.

\section{Acknowledgements}

The Authors would like to thank to EFOP-3.6.1-16-2016-00017 'Internationalization, initiatives to establish a new source of researchers and graduates, and development of knowledge and technological transfer as instruments of intelligent specializations at Széchenyi István University' for the support of the research.

\section{Open Access statement}

This is an open-access article distributed under the terms of the Creative Commons Attribution 4.0 International License (https://creativecommons.org/licenses/by/4.0/), which permits unrestricted use, distribution, and reproduction in any medium, provided the original author and source are credited, a link to the CC License is provided, and changes - if any - are indicated. (SID_1)

\section{References}

[1] Hajdu F., Kuti R. Examination of chaotic vibrations during operation of a fire truck, Proceedings of MAC 2018 in Prague, Prague, Czech Republic, 25-27 May 2018, pp. 163-170.

[2] Marzbanrad J., Keshavarzi A. Chaotic vibrations of a nonlinear air suspension system under consecutive half sine speed bump, Indian Journal of Science \& Technology, Vol. 8, No. 3, 2015, pp. 72-84.

[3] Fakhraei J., Khanlo H. M., Ghayour M. Chaotic behaviors of a ground vehicle oscillating system with passengers, Scientia Iranica, Vol. 24, No. 3, 2017, pp. 1051-1068.

[4] Sendur P., Kurtdere A., Akalyar O. A methodology to improve steering wheel vibration of a heavy commercial truck, Technical Paper, No. 2013-01-2351, Society of Automotive Engineers, 2013.

[5] Patricio P. S. Effects of frame design and cab suspension on the ride quality of heavy trucks, MSc Thesis, Virginia Polytechnic Institute and State University, 2002.

[6] Yenerer H., Stan A. C., Sendur P., Basdogan I. Vibro-acoustic analysis of a heavy duty truck cabin, ASME, 2014 12th Biennial Conference on Engineering Systems Design and Analysis, Copenhagen, Denmark, 25-27 July 2014, Paper No. ESDA2014-20559, pages 7 . 
[7] Li S., Lu Y., Li L. Dynamical test and modeling for hydraulic shock absorber on heavy vehicle under harmonic and random loadings, Research Journal of Applied Sciences, Engineering and Technology. Vol. 4, No. 13, 2012, pp. 1903-1910.

[8] Gagliardi J. C., Utt W. K. Vibration environmental testing for large haulage trucks, Report of Investigations 9483, United States Department of The Interior Bureau of Mines, 1993.

[9] Böröcz P., Pidl R. Measurement and analysis of vibrations of express small freight vehicles in Hungary for packaging testing purposes (in Hungarian), Logisztikai Évkönyv, 2018, pp. 46-55.

[10] Vaccaro B. Real-life fire engine driving simulator: Apparatus innovations, Fire Rescue, Vol. 4, No. 8, 2009, https://www.firerescuemagazine.com/articles/print/volume-4/issue-8/ apparatus-innovations/real-life-fire-engine-driving-simulator.html (last visited 5 December 2018).

[11] Horváth G., Kuti R. Tasks of the head of rescue operations to eliminate accidents during hazardous substances transportation by motor vehicles (in Russian) Pozhary $i$ Chrezvychajnye Situacii, Predotvrashenie Likvidacia, Vol. 1, 2017, pp. 30-34.

[12] Łopatka M. J., Muszyński T., Rubiec A. Simulation identification of fire rescue robot suspension loads, 18th International Conference on Methods \& Models in Automation \& Robotics, Miedzyzdroje, Poland, 26-29 August 2013, Paper No. 13933303.

[13] Szauter F. Dynamic modeling, identification and vibration analysis of road vehicles (in Hungarian), PhD Thesis, Széchenyi István University, 2017.

[14] Szauter F., Istenes G., Rödönyi G. AR and ARMA spectral analysis of suspension system of a commercial city bus, IEEE 17th International Symposium on Computational Intelligence and Informatics, Budapest, Hungary, 17-19 November 2016, Paper No. 16666841.

[15] Zhao L., Zhou C., Yu Y., Yang F. A method to evaluate stiffness and damping parameters of cabin suspension system for heavy truck, Advances in Mechanical Engineering, Vol. 8, No. 7, 2016, pp. 1-9.

[16] Iwaniec J. Identification of car suspension system parameters on the basis of exploitational measurements, Diagnostyka, Vol. 14, No. 2, 2013, pp. 11-16.

[17] Ledwidge J. System identification and parameter estimation of a motorcycle suspension system, MSc Thesis, Dublin City University, 1995.

[18] Pence B. L., Fathy H. K., Stein J. L. Sprung mass estimation for off-road vehicles via baseexcitation suspension dynamics and recursive least squares, American Control Conference, St. Louis, MO, USA, 10-12 June 2009, Paper No. 10775323.

[19] Hostettler R., Birk W., Nordenvaad M. L. Extended Kalman filter for vehicle tracking using road surface vibration measurements, IEEE 51st IEEE Conference on Decision and Control, Maui, HI, USA, 10-13 December 2012, Paper No. 13289072.

[20] Thaller S., Reiterer F., Waschl R. S. H., Kokal H., del Re L. Fast determination of vehicle suspension parameters via continuous time system identification, IFAC-PapersOnLine, Vol. 49, No. 11, 2016, pp. 448-453.

[21] Alvarez-Sánchez E. A quarter-car suspension system: car body mass estimator and sliding mode control, Procedia Technology, Vol. 7, 2013, pp. 208-214.

[22] Yarmohamadi H. Advances in heavy vehicle dynamics with focus on engine mounts and individual front suspension, $P h D$ Thesis, Chalmers University of Technology, Göteborg, Sweden, 2012.

[23] Björklund M. A model of the air temperature in a truck cabin, MSc Thesis, Kungliga Tekniska Högskolan, Royal Institute of Technology, Stokholm, 2004.

[24] Hajdu F., Lakatos I., Körös P. Lithium battery modeling in Simulink environment (in Hungarian), Innováció és fenntartható felszíni közlekedés konferencia, Budapest, Hungary, 29-31 August 2012, pp. 132-140. 
[25] Lakatos I., Körös P., Hajdu F. Examination of the effect of sensor properties on the secondary battery model in simulation environment, Acta Technica Jaurinensis, Vol. 7, No. 1, 2014, pp. 71-86.

[26] Lu Y., Li S., Chen N. Research on damping characteristics of shock absorber for heavy vehicle, Research Journal of Applied Sciences, Engineering and Technology Vol. 5, No. 3, 2013, pp. 842-847.

[27] Schiffer A., Ivanyi A. Two-dimensional vector hysteresis model, Pollack Periodica, Vol. 1, No. 2, 2006, pp. 83-97.

[28] Pop N. A., Caltun O. F. Algorithm to describe magnetization curves by using Jiles Atherton model, Pollack Periodica, Vol. 5, No. 3, 2010, pp. 155-165.

[29] Csurcsia P. Static nonlinearity handling using best linear approximation: An introduction, Pollack Periodica, Vol. 8, No. 1, 2013, pp. 153-165.

[30] Strejc V. Least squares parameter estimation, Automatica, Vol. 16, No. 5, 1980, pp. 535-550.

[31] OPTI Toolbox Wiki, Invers problem limited, https://inverseproblem.co.nz/OPTI/index.php/ Main/HomePage (last visited 10 September 2018).

[32] Zhao F., Dong M., Qin Y., Gu L., Guan J. Adaptive neural-sliding mode control of active suspension system for camera stabilization, Shock and Vibration, No. 2, 2015, pp. 1-8.

[33] Hassaan G. A. Car dynamics using quarter model and passive suspension, Part I, Effect of suspension damping and car speed, International Journal of Computer Techniques, Vol. 1, No. 2, 2014, pp. 1-9.

[34] Doumiati M., Victorino A., Charara A., Baffet G., Lechner D. An estimation process for vehicle wheel-ground contact normal forces, Proceedings of the 17th World Congress The International Federation of Automatic Control, Seoul, Korea, 6-11 July, 2008, pp. 7110-7115.

[35] Jiao L. Vehicle model for tyre-ground contact force evaluation, MSc Thesis, Kungliga Tekniska högskolan, Royal Institute of Technology, Stokholm, 2013.

[36] Shi W. K., Liu C., Chen Z. Y., He W., Zu Q. H. Efficient method for calculating the composite stiffness of parabolic leaf springs with variable stiffness for vehicle rear suspension, Mathematical Problems in Engineering, Vol. 2016, Paper ID 5169018, pages $1-12$.

[37] Sokol M., Venglár M. System identification of a composite beam, Pollack Periodica, Vol. 12, No. 3, 2017, pp. 43-54.

[38] Anjish M. G., Sarathd S. Design and analysis of leaf spring by using hybrid composite material, International Research Journal of Engineering and Technology, Vol. 4, No. 4, 2017, pp. 2235-2241. 